\title{
Inter- and intraspecific interactions in two mealybug predators Spalgis epius and Cryptolaemus montrouzieri in the presence and absence of prey
}

\author{
A.S. Dinesh and M.G. Venkatesha* \\ Department of Zoology, Bangalore University, Jnanabharathi, Bengaluru \\ 560056, Karnataka, India
}

\begin{abstract}
Spalgis epius and Cryptolaemus montrouzieri are the two potential predators of different species of mealybugs. However, the mode of their interactions is not known to use these predators together in the field. Hence, we investigated on the possible interactions i.e., cannibalism, intraguild predation (IGP) and competition between the predators in the presence and absence of prey Planococcus citri. In the presence of prey, no cannibalism and predation were observed in both S. epius and C. montrouzieri larvae. A pair of S. epius larvae consumed significantly more number of mealybugs than one S. epius/C. montrouzieri larva or a pair of $C$. montrouzieri larvae. The predation of S. epius larva by $C$. montrouzieri larva was significantly more than the predation of C. montrouzieri by S. epius. Conspecific and interspecific egg predation was absent both in S. epius and C. montrouzieri. Cannibalism in C. montrouzieri was more than that in S. epius. The study indicated that $C$. montrouzieri larvae can be used as an additive along with voracious $S$. epius larvae under abundant prey population. IGP was asymmetric between the two predators in the absence of prey. Both S. epius and C. montrouzieri larvae can maintain a stable coexistence when prey is abundantly available, however, in the complete absence of prey C. montrouzieri may dominate the guild. This study provides an insight into the possible complex inter- and intraspecific predatory phenomena in the field to use these two predators in the biological control of mealybugs.
\end{abstract}

Keywords: inter- and intraspecific interactions, cannibalism, intraguild predation, Spalgis epius, Cryptolaemus montrouzieri, Planococcus citri

(Accepted 30 July 2013; First published online 18 September 2013)

\section{Introduction}

Fundamental question in biological control is how multiple predators interact collectively to suppress the populations of herbivorous pests (Denoth et al., 2002; Wilby \& Thomas, 2002; Symondson et al., 2002; Cardinale et al., 2003; Mills, 2006).

*Author for correspondence

Phone: +91 9448689080

Fax: 918023211020

E-mail: venkatmelally@gmail.com
Inter- and intraspecific competitions are important interactions among organisms which share the same food. Cannibalism and intraguild predation (IGP) have attracted much attention as these interactions are significant and widespread among many taxa of predatory arthropods. In biological communities, complex interactions and more specifically cannibalism and IGP are considered as key determinants of population dynamics and community structure (Polis \& Holt, 1992; Wagner \& Wise, 1996; Holt \& Polis, 1997). Cannibalism and IGP determine the fate of a community (Godfray \& Pacala, 1992). IGP could be either symmetric when species are mutual predators of one another or 
asymmetric when one species consistently prey upon the other (Polis et al., 1989). Thus, IGP may have a negative effect on the outcome of biological control (Snyder \& Ives, 2001; Rosenheim, 2005). However, studies have shown that the incidence of IGP could have a positive effect on biocontrol of pests (Schausberger \& Walzer, 2001; Snyder et al., 2004; Gardiner \& Landis, 2007). In pest management, usage of multiple predators remains contentious, as there are extensive data both for and against the suppression of pest populations (Denno \& Finke, 2006). There are evidences showing that multiple natural enemies can exert a strong collective control on agricultural pests (Symondson et al., 2002; Cardinale et al., 2003). Yet, some studies confirmed that employing multiple agents to control pest herbivores disrupt biological control (Snyder \& Ives, 2001; Prasad \& Snyder, 2004). The ability of a natural enemy complex to curtail a pest population is depending on the strength of interactions among themselves. There is a possibility that multiple predators may interact synergistically to enhance pest suppression (Losey \& Denno, 1999) or their effects on pest populations are simply additive when they do not interact at all (Chang, 1996; Straub \& Snyder, 2006). However, some species of predators may interact antagonistically wherein they consume each other, which affect pest control (Finke \& Denno, 2003; Prasad \& Snyder, 2004). A few are known about the basic components of these interactions, which are directly associated with cannibalism and IGP in ladybird beetles (Yasuda et al., 2001). Thus, in a biological control perspective it becomes essential to critically assess the nature of interactions (i.e., antagonistic, synergistic or no interaction between predators), the frequency and strength of such interactions in the food web, how such interactions affect pest suppression, and how habitat and landscape structures might rage predator-predator interactions (Denno \& Finke, 2006).

Several species of mealybugs (Hemiptera: Pseudococcidae) are serious pests on various crops e.g., coffee, citrus, cocoa, guava, grapes, papaya, cotton, mango, mulberry, vegetable crops, ornamental plants, etc. worldwide (Browning, 1992; Franco et al., 2001; Dinesh \& Venkatesha, 2011a,b). Mealybugs possess a protective wax body coating and have the ability of being protected inside bark crevices and other inaccessible parts of plants; hence satisfactory control measures have not been achieved with insecticides (Joyce et al., 2001). Thus, management of mealybugs by biological control provides a sustainable and efficient control approach (Bentley, 2002).

The apefly Spalgis epius (Westwood) (Lepidoptera: Lycaenidae) is a potential predator of different species of mealybugs (Dinesh \& Venkatesha, 2011a,b). S. epius occurs in India, Burma, Sri Lanka, Philippines, Java, Bangladesh, Thailand and Krakatau Island (Indonesia) (see Dinesh \& Venkatesha, 2011a). Studies on the biology, development, mating and egg laying behaviour, feeding potential and mass rearing of $S$. epius have been conducted (Venkatesha et al., 2004, 2005; Venkatesha \& Shashikumar, 2006; Dinesh et al., 2010; Dinesh \& Venkatesha, 2011a,b, 2012, 2013a,b; Venkatesha \& Dinesh, 2011). S. epius has four larval instars and completes its life cycle in 23.8 days at laboratory condition (Dinesh et al., 2010).

Another mealybug predator Cryptolaemus montrouzieri Mulsant (Coleoptera: Coccinellidae) is one of the most widely used natural enemies of mealybugs (Heidari \& Copland, 1992; Perez-Jaggi, 1995). Both adults and larvae of C. montrouzieri actively search for prey on vegetation and consume all stages of mealybugs (Clausen, 1978). C. montrouzieri has four larval instars and completes its life cycle in 28.4 days at laboratory condition (Mani \& Thontadarya, 1987).

S. epius and C. montrouzieri found to coexist in agricultural fields sharing common prey resources (Mani, 1995). Although both the predators are considered as potential predators of various species of mealybugs, no information is available about their interactions in the presence and absence of a prey species to utilize these predators together in the field as biocontrol agents against mealybugs. Hence, a study was carried out to explore the role of IGP, cannibalism and competition as possible mechanisms to understand a relationship between these two predators. Further, to assess whether the combination of these two major predators could result in a better biological control of mealybugs in the field, we tested their voracity on mealybugs.

\section{Materials and methods}

\section{Laboratory rearing of S. epius and $\mathrm{C}$. montrouzieri}

To rear S. epius and C. montrouzieri in the laboratory, their host mealybug Planococcus citri (Risso) was cultured on pumpkins (Cucurbita maxima Duchesne) as described by Serrano \& Lapointe (2002). S. epius and C. montrouzieri were reared separately on the mealybug-infested pumpkins at $28 \pm 1^{\circ} \mathrm{C}, 65 \pm 5 \% \mathrm{RH}$ and photoperiod 12:12 L:D in an environment chamber following the methods of Chacko et al. (1978) and Venkatesha \& Dinesh (2011). All experiments were conducted at $28 \pm 1^{\circ} \mathrm{C}, 65 \pm 5 \% \mathrm{RH}$ and photoperiod 12:12 $\mathrm{L}: \mathrm{D}$ in an insect environment chamber.

\section{Interaction and voracity of two predators}

To study the interaction and prey consumption of S. epius and $C$. montrouzieri, plastic cups $(5 \mathrm{~cm}$ diameter) with cutopened bottom were fixed on the surface of a pumpkin using melted paraffin wax and this served as an arena for the experiment. Through the open end of the cup, 200 mealybug crawlers (first instar nymphs) were released on the pumpkin and the mouth of the cup was closed using muslin cloth. When nymphs reached the adult stage, the number of adult mealybugs present inside the cup was counted and the newly hatched first instar larva of S. epius and C. montrouzieri were released into the cup in three different combinations: (a) one larva each of S. epius and C. montrouzieri, (b) two larvae of C. montrouzieri, and (c) two larvae of S. epius. Observations were made on inter- and intraspecific larval interactions, their feeding behaviour and the number of prey consumed in the three combinations. Observations were made daily 5-6 times for about $2 \mathrm{~h}$ at an interval of 3-4h until all the larvae pupated. Each experiment was replicated five times with ten trials per replication.

\section{Interspecific interaction in the absence of prey}

All the four larval instars of S. epius and C. montrouzieri were collected from mealybug-infested pumpkins and kept individually in Petri dishes ( $5 \mathrm{~cm}$ diameter). These larvae were starved for $12 \mathrm{~h}$ to induce hunger. Larvae of identical age and size were used based on the day of their ecdysis. In the first set of experiment, to investigate interactions between the similar instar larvae of S. epius and C. montrouzieri, a single first instar larva of both S. epius and C. montrouzieri were transferred to a clean Petri dish $(5 \mathrm{~cm}$ diameter) at opposite poles with the 
help of a single-bristle paintbrush. The mode of interaction between the two larvae was recorded after $24 \mathrm{~h}$. Similarly, experiments were conducted for the second, third and fourth instar larvae of the two predators. Each combination was replicated 50 times.

In the second set of experiment, IGP studies were conducted in two different combinations: (a) younger instar larva of S. epius vs. one instar older larva of C. montrouzieri (i.e., I instar S. epius larva vs. II instar C. montrouzieri larva, II instar S. epius larva vs. III instar C. montrouzieri larva, and III instar S. epius larva vs. IV instar C. montrouzieri larva) and (b) younger instar larva of $C$. montrouzieri vs. one instar older larva of S. epius (i.e., I instar C. montrouzieri larva vs. II instar S. epius larva, II instar C. montrouzieri larva vs. III instar S. epius larva, and III instar C. montrouzieri larva vs. IV instar S. epius larva). Based on the day of larval ecdysis, larval instars were determined and utilized in the experiment. In all combinations one larva of each predator was used. Each experiment was replicated 50 times. Larvae were transferred to a Petri dish at opposite poles and the modes of interactions were recorded after $24 \mathrm{~h}$.

\section{Intraspecific interaction in the absence of prey}

In the first set of experiment, intraspecific interactions were studied both in S. epius and C. montrouzieri. Two first instar S. epius larvae of identical age and size were transferred to a Petri dish at opposite poles, and the type of interaction between them was noted after $24 \mathrm{~h}$. Similarly, experiments were conducted for the second, third and fourth instar larvae of S. epius and C. montrouzieri separately. Each larval combination was replicated five times with ten trials per replication.

In the second set of experiment, intraspecific interaction studies were conducted in two different combinations: (a) younger instar larva of S. epius vs. one instar older larva of S. epius (i.e., I instar larva vs. II instar larva, II instar larva vs. III instar larva, and III instar larva vs. IV instar larva) and (b) younger instar larva of C. montrouzieri vs. one instar older larva of C. montrouzieri (i.e., I instar larva vs. II instar larva, II instar larva vs. III instar larva, and III instar larva vs. IV instar larva). In all combinations a newly moulted single larva from each instar of the predators was used. Larvae were transferred to a Petri dish at opposite poles and the modes of interactions were recorded after $24 \mathrm{~h}$. Each experiment was replicated five times with ten trials per replication. The percentage of cannibalism was calculated in each combination for both the predators.

\section{Egg, prepupa and pupal predation/cannibalism}

Egg, prepupa and pupal predation/cannibalism studies were conducted in five different combinations: (a) ten eggs of S. epius vs. one I/II/III/IV instar larva of S. epius, (b) ten eggs of C. montrouzieri vs. one I/II/III/IV instar larva of C. montrouzieri, (c) ten eggs of S. epius vs. one I/II/III/IV instar larva of C. montrouzieri, (d) ten eggs of C. montrouzieri vs. one I/II/III/IV instar larva of S. epius, and (e) ten eggs, one larva each from four larval instars, one prepupa and one pupa of S. epius independently vs. one adult of C. montrouzieri. As $S$. epius adults are non-predacious and feed on nectar/water, they were not utilized in the experiment like $C$. montrouzieri adults. Thus, there were eight intraspecific and 15 interspecific combinations. Each experiment was replicated five times with ten trials per replication.

\section{Data analysis}

The outcome of interspecific interactions was classified as: S. epius acted as an intraguild (IG) prey, S. epius acted as an IG predator or no incidence of IGP occurred. For each speciespair comparison, the level of IGP between S. epius larvae and C. montrouzieri larvae was determined as the proportion of replicates in which IGP occurred out of the total number of replicates for that combination. Following the method of Lucas et al. (1998) an index of symmetry was measured by the proportion of replicates in which S. epius was the IG predator out of the total number of replicates wherein IGP occurred. Thus, a symmetry index of $>0.5$ IGP was in favour of $S$. epius, while an index of $<0.5$ IGP was in favour of $C$. montrouzieri. The symmetry indices for each combination were compared with the theoretical index of $50 \%$ corresponding to a symmetrical interaction, using a Chi-square test $\left(\chi^{2}, P<0.05\right)$ (SPSS Inc. 2008). The symmetry of IGP between S. epius and C. montrouzieri at different larval instar was analysed by using the binomial test, the null hypothesis being that predation is equally likely to occur in both the ways. The strength of IGP between the two species of predators for a given combination was assessed using the $\chi^{2}$ test with an expected value of $50 \%$ and was considered (i) symmetrical, when the $\chi^{2}$ value was not significant, wherein the rate of predation of the two predators was similar, (ii) asymmetrical, when the $\chi^{2}$ value was significant, in which the rate of predation of the two predators was different, and (iii) not significantly asymmetrical, when the $\chi^{2}$ value was not significant, wherein the rate of predation of the two species not much differed.

The voracity of larvae in different combinations was subjected to analysis of variance (ANOVA). When ANOVA was significant at the $P<0.05$ level, differences were determined by post hoc Tukey's HSD (Honestly Significant Difference) multiple range test at probability level $P<0.05$ as significant (SPSS Inc. 2008). The percentage of cannibalism in each experimental combination and overall predation (i.e., pooled data of the percentage of predation/cannibalism) in both species were arcsin transformed and subjected to nonparametric analysis of variance using Kruskal-Wallis test. A non-parametric approach was used because of heteroscedasticity and departures from normality (Zar, 1984). When significant difference was found in Kruskal-Wallis test at the $P<0.05$ level, multiple pairwise Mann-Whitney $U$ test was used to know the differences in the cannibalism in different larval instars of each predator and overall predation and cannibalism in both the predators. Alpha values were adjusted according to the Bonferroni correction for multiple comparisons (referred to in text as $\alpha \mathrm{B}$ ).

\section{Results}

\section{Interaction and voracity of two predators}

In the presence of prey, no cannibalism and predation were observed both in S. epius and C. montrouzieri larvae. When C. montrouzieri and S. epius larvae were maintained together, they fed on prey at different places in the arena. $S$. epius larva was found feeding continuously throughout its development, whereas $C$. montrouzieri larva was feeding and resting at times. A pair of $S$. epius larvae consumed more 
Table 1. Interspecific interaction between Spalgis epius and Cryptolaemus montrouzieri.

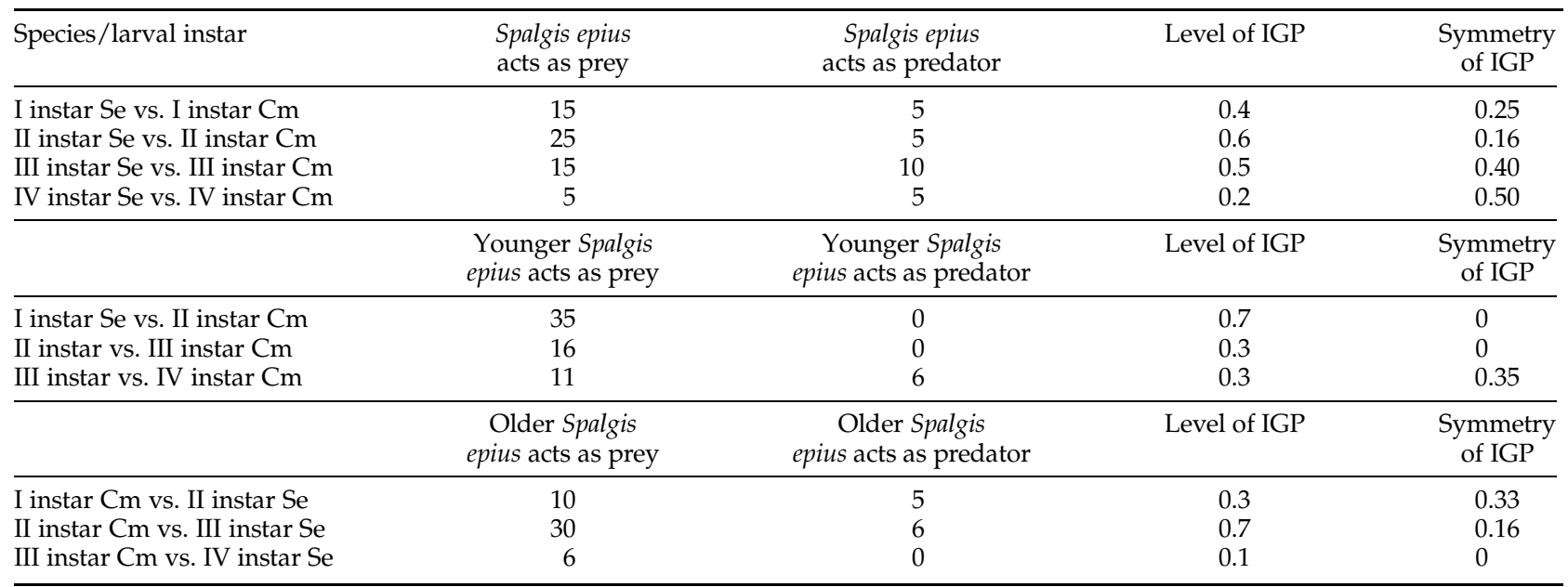

Se- Spalgis epius. $\mathrm{Cm}$ - Cryptolaemus montrouzieri. $\mathrm{N}=50$ for each pairing.

number of mealybugs compared to one larva of S. epius/ C. montrouzieri or two larvae of $C$. montrouzieri $\left(F_{2,12}=545.14\right.$; $P<0.05$ ) (fig. 1).

\section{Interspecific interaction in the absence of prey}

The level and symmetry index of IGP between S. epius and C. montrouzieri from first to fourth instar larvae is presented in table 1. In interactions between the similar larval instars of two predators, IGP was significantly asymmetrical and in favour of $C$. montrouzieri in the first $\left(\chi_{1}^{2}=5 ; P<0.05\right)$ and second instar larvae $\left(\chi^{2}{ }_{1}=13.3 ; P<0.05\right)$ (fig. $\left.2 \mathrm{~A}\right)$. Whereas, IGP was symmetrical in the third $\left(\chi^{2}{ }_{1}=1 ; P=0.317\right)$ and fourth $\left(\chi^{2}=0 ; P=1\right)$ larval instar combinations of the two predators (fig. 2A).

In interactions between younger $S$. epius and older C. montrouzieri larval instars, IGP was significantly asymmetrical and exclusively in favour of older $C$. montrouzieri against the first $\left(\chi^{2}{ }_{1}=35 ; P<0.05\right)$ and second $\left(\chi^{2}{ }_{1}=16 ; P<0.05\right)$ instar larvae of $S$. epius. IGP was not significantly asymmetrical between the third instar larva of $S$. epius and the fourth instar larva of $C$. montrouzieri $\left(\chi_{1}^{2}=1.47 ; P=0.225\right)$ (fig. $2 B$ ).

In interactions between older $S$. epius and younger C. montrouzieri larval instars, IGP was not significantly asymmetrical between the second instar larva of S. epius and the first instar larva of $C$. montrouzieri $\left(\chi_{1}^{2}=1.6 ; P=0.196\right)$. Whereas, IGP was significantly asymmetrical and in favour of younger $C$. montrouzieri against the third $\left(\chi_{1}^{2}=16 ; P<0.05\right)$ and fourth $\left(\chi_{1}^{2}=6 ; P<0.05\right)$ instar larvae of $S$. epius (fig. $2 \mathrm{C}$ ).

\section{Intraspecific interaction in the absence of prey}

In intraspecific interactions between the same larval instars of S. epius, cannibalism was significantly different among four larval instars $\left(H_{3}=14.35 ; P<0.05\right)$. Cannibalism was maximum in the third instar larva compared to other larval instars, and it was significantly different from the first $(\alpha \mathrm{B} 6$ tests; $P=0.008)(U=0.00 ; P=0.006)$ and fourth $(U=0.00 ; P=0.007)$ instar larvae (fig. 3A). Similarly, in C. montrouzieri there were significant differences in cannibalism among different larval

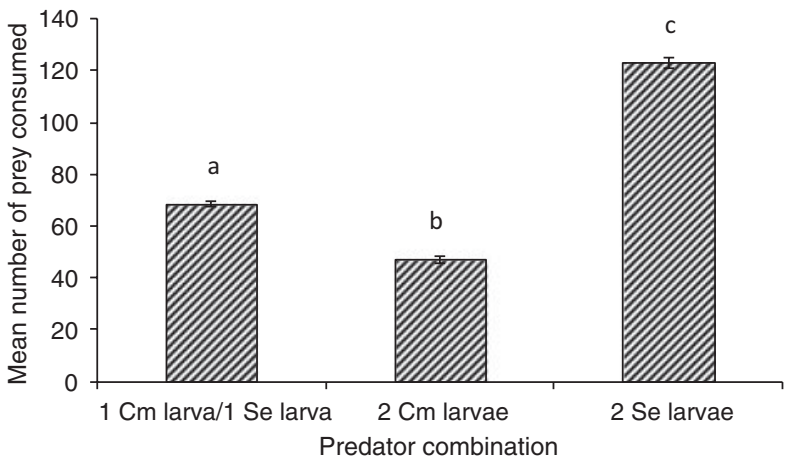

Fig. 1. Mean $( \pm \mathrm{SE})$ voracity of Spalgis epius (Se) and Cryptolaemus montrouzieri $(\mathrm{Cm})$ larvae. Bars with different letters indicate the significant difference in the number of prey consumed (ANOVA; Tukey HSD test $P<0.05)$. Vertical lines indicate the SE of the mean number of prey consumed.

instars $\left(H_{3}=15.84 ; P<0.05\right)$. Cannibalism was greater in the first and second instar larvae than in the third and fourth instar larvae $(P<0.008)$ (fig. 3B).

In conspecific interactions between young and one instar older larva of S. epius, cannibalism was significantly different in different larval instars of S. epius (i.e., older larval instars cannibalized on younger larval instars: $H_{2}=11.29 ; P<0.05$ and younger larval instars cannibalized on older larval instars: $\left.H_{2}=11.35 ; P<0.05\right)$. The third instar larva of $S$. epius was significantly more cannibalistic both on second ( $\alpha \mathrm{B} 3$ tests; $P=0.016) \quad(U=0.00 ; \quad P=0.005)$ and fourth instar larvae $(U=0.00 ; P=0.006)$ than other larval instars (fig. $4 \mathrm{~A})$. Whereas, the second instar larva of $C$. montrouzieri was significantly more cannibalistic on first instar larva than other larval instars $\left(H_{2}=10.72 ; P<0.05\right)(\alpha \mathrm{B} 3$ tests; $P=0.016)$ $(U=0.00 ; P=0.007$ ) (fig. $4 \mathrm{~B})$. Cannibalism by younger larva on older $C$. montrouzieri larva was minimum and there were no significant differences among different larval instars $\left(H_{2}=4.04 ; P=0.132\right)$ (fig. 4B). 


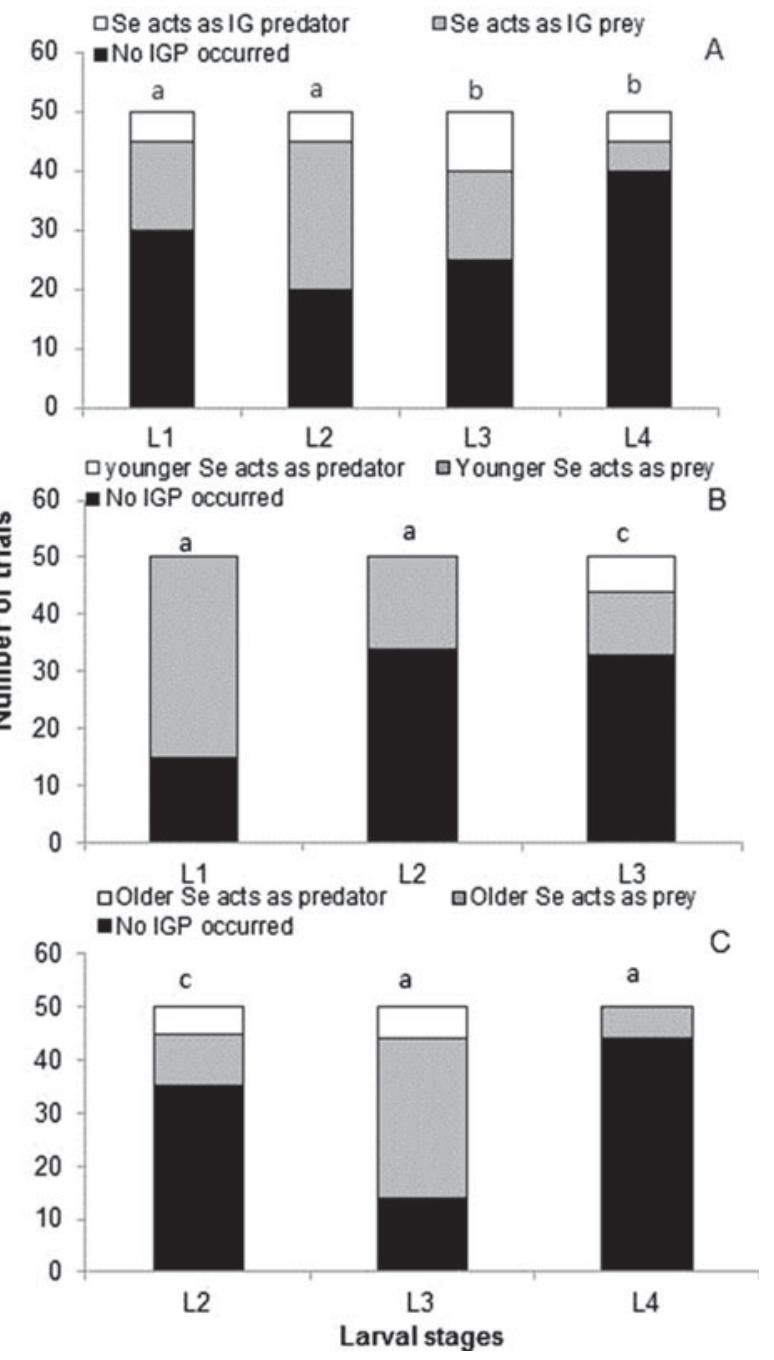

Fig. 2. Symmetry of IGP between Spalgis epius and Cryptolaemus montrouzieri. (A) IGP between similar instar larvae, (B) IGP between younger $S$. epius and older $C$. montrouzieri larvae and (C) IGP between older $S$. epius younger $C$. montrouzieri larvae. Analysis shows that larval instars marked a, IGP was asymmetric; larval instars marked b, IGP was symmetric; and larval instars marked c, IGP was not significantly asymmetric.

\section{Overall predation/cannibalism}

Overall predation between S. epius larva and C. montrouzieri larva was significantly different $\left(H_{3}=64.47 ; P<0.05\right)$. Overall predation of S. epius larva by C. montrouzieri larva was significantly more than that of $C$. montrouzieri by S. epius ( $\alpha \mathrm{B} 6$ tests; $P=0.008)(U=147.0 ; P<0.0001)($ fig. 5$)$. Overall cannibalism was more in C. montrouzieri larva than that in S. epius larva and it was not significantly different $(U=987.0 ; P=0.062)$ (fig. 5).

\section{Egg, prepupa and pupal predation/cannibalism}

Conspecific and interspecific egg predations were absent both in S. epius and C. montrouzieri larvae in the absence and presence of prey. C. montrouzieri adults predated on all larval

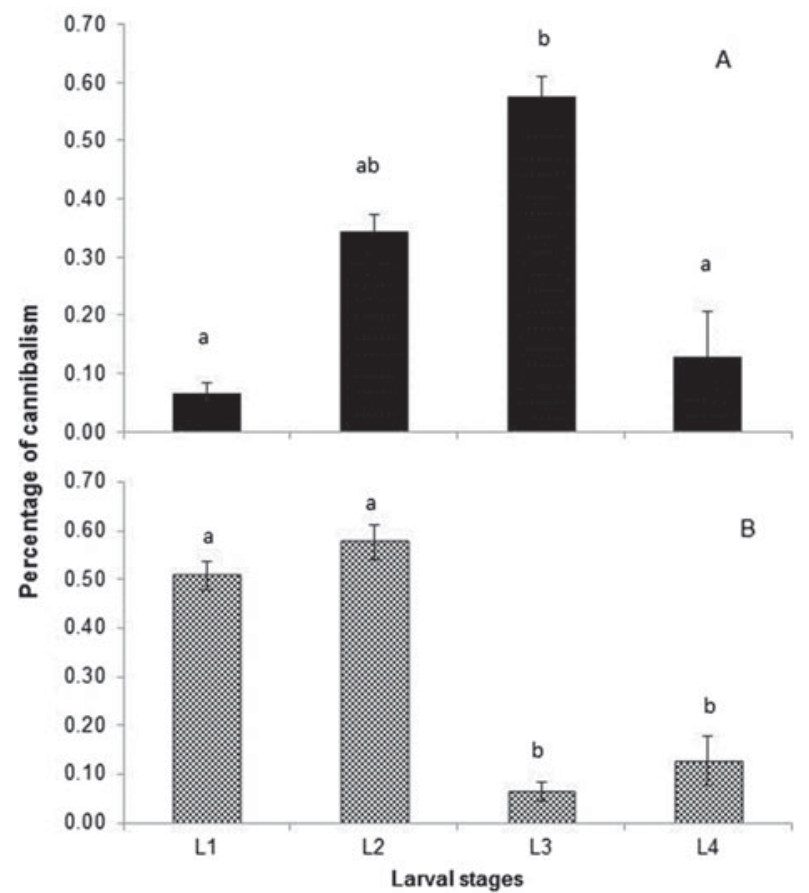

Fig. 3. Mean $( \pm S E)$ percentage of cannibalism in the same larval instars of Spalgis epius (Se) and Cryptolaemus montrouzieri $(\mathrm{Cm})$ in the absence of prey. (A) Se cannibalized by Se, (B) Cm cannibalized by $\mathrm{Cm}$. Bars with different letters indicate the significant difference in the percentage of cannibalism (Mann-Whitney $U$ test $\alpha \mathrm{B}$ $P<0.008)$. Vertical lines indicate the SE of the mean number of percentage of cannibalism.

instars, prepupa, and fresh pupa of S. epius in the absence of prey. Except the first instar larva of S. epius and C. montrouzieri, all larval instars of both the predators attacked the prepupa and fresh pupa of S. epius in the absence of prey. In C. montrouzieri no larval instars attacked conspecific pupa.

\section{Discussion}

The results of our study indicated that no cannibalism and predation exist both in S. epius and C. montrouzieri in the presence of prey. S. epius is known to deposit a maximum number of eggs on the mealybug-infested pumpkins containing conspecific eggs (Dinesh \& Venkatesha, 2013b), which may be because of the absence of egg/larval cannibalism. Maximum prey consumption in combination of two S. epius larvae may be due to their voracious and continuous feeding habit. Thus, S. epius could be a potential predator of mealybugs as reported by Dinesh and Venkatesha $(2011 a, b)$. When S. epius larvae voraciously fed on the main mass of mealybugs, C. montrouzieri larvae cleared leftover eggs, nymphs, and halfeaten adults of mealybugs from the margin. The coexisting feeding behaviour of these two predators could be additive in the suppression of pest populations. Larvae of both S. epius and $C$. montrouzieri known to coexist in agricultural fields sharing common prey resources and successfully reducing prey populations (Mani, 1995).

IGP and cannibalism are two important mortality factors in predators and these could be a regulatory mechanism 


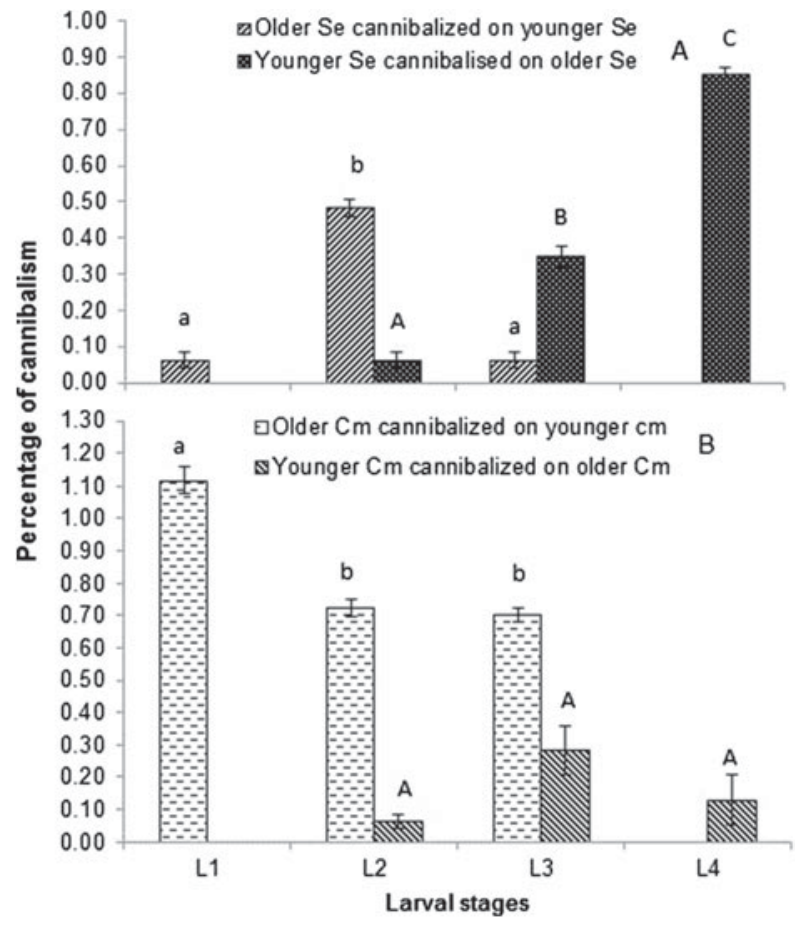

Fig. 4. Mean $( \pm S E)$ percentage of cannibalism in different larval instars of Spalgis epius (Se) and Cryptolaemus montrouzieri (Cm) in the absence of prey. (A) older and younger Se cannibalized on younger and older Se, (B) older and younger $\mathrm{Cm}$ cannibalized on younger and older $\mathrm{Cm}$. Bars with different letters indicate the significant difference in the percentage of cannibalsm (MannWhitney $U$ test $\alpha \mathrm{B} P<0.016)$. Vertical lines indicate the $\mathrm{SE}$ of the mean number of percentage of predation.

of population growth operating through a negative densitydependent feedback. IGP is generally considered as an important mechanism underlying the success of biological control (Grez et al., 2012). Asymmetrical IGP in favour of C. montrouzieri larvae in the absence of prey could be due to the sluggish nature of $S$. epius larvae, which are more prone to interspecific attack. Larvae of S. epius mimic a mealybug colony by placing the mealybug debris on their back (Dinesh et al., 2010) and thus escape from the attack of mealybug attendant ants (Venkatesha et al., 2004). However, in the absence of mealybugs, exposed larvae of S. epius may be prone to interspecific attack by $C$. montrouzieri larvae. Similarly, the coccinellid aphid predator Harmonia axyridis (Pallas) feeds on lepidopterous larvae in the absence of its prey (Kim et al., 1968; Shu \& Yu, 1985; Hoogendoorn \& Heimpel, 2003; Koch et al., 2003). In the absence of prey, predation between C. montrouzieri and S. epius is similar to that reported among predatory coccinellids under scarce prey density (Hironori \& Katsuhiro, 1997; Schellhorn \& Andow, 1999; Musser \& Shelton, 2003).

Maximum cannibalism by the third instar larva of S. epius could be due to their voracious feeding habit, which consumes a large quantity of prey compared to other larval stages (Dinesh \& Venkatesha, 2011a, b). Among younger and older conspecific larval interactions, the third instar larva of S. epius was more cannibalistic as it attacked both the smaller second instar and the sluggish fourth instar larva. Conspecific predation in Lepidoptera with a moderate food supply or

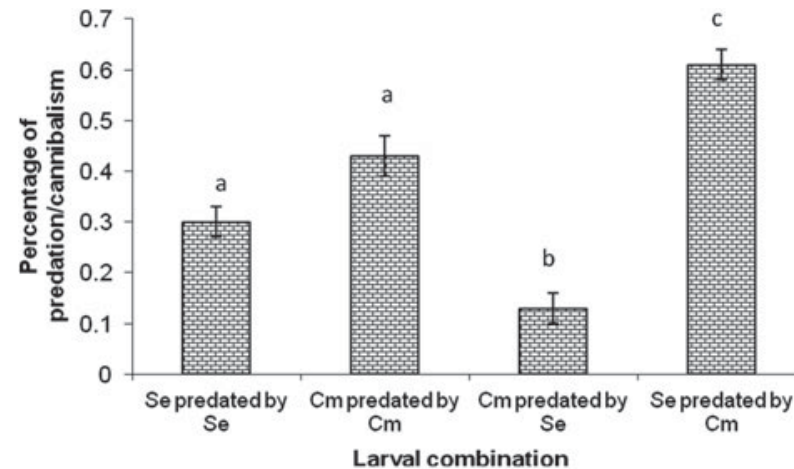

Fig. 5. Mean $( \pm \mathrm{SE})$ percentage of cannibalism and predation in Spalgis epius (Se) and Cryptolaemus montrouzieri $(\mathrm{Cm})$ in the absence of prey. Bars with different letters indicate the significant difference in percentage of predation/cannibalism (MannWhitney $U$ test $\alpha \mathrm{B} P<0.008$ ). Vertical lines indicate the SE of the mean number of percentage of predation.

no food is common and the smallest, less healthy or less active larvae are usually attacked by more robust individuals (Dethier, 1937).

All larval instars of C. montrouzieri potentially predated on all larval instars of S. epius in the absence of prey. The relative aggressive behaviour of hungry larvae of $C$. montrouzieri towards S. epius may be because of their active movement compared to S. epius larvae. A greater cannibalistic nature of older larval instars of $C$. montrouzieri on first instar larva may be due to their differences in their body size. Moreover, the incidence of conspecific and heterospecific predation is greater when an attacker is one instar older and thus, bigger in size than its victim (Omkar et al., 2005). As well, in most of ladybird species older larvae move faster than young larvae $(\mathrm{Ng}, 1988)$, thus fast moving older larval instars of C. montrouzieri easily attack and consume younger larval instars. Moreover, the bioconversion efficiency of older larval instars in predatory coccinellids is less than that of younger larvae, which suggests that older larvae feed more and convert less prey biomass into predator biomass because of high metabolic cost (Baumgartner et al., 1987). Hence, requirement of more food intake in older larval instars of $C$. montrouzieri may drive them to increasingly indulge in cannibalism as well as IGP.

Absence of interspecific predation of eggs of C. montrouzieri by $S$. epius may be because coccinellid eggs are protected from defensive alkaloids such as pyrazines and quinolones (Agarwala \& Yasuda, 2001). Hence, eggs of coccinellids are less attacked by predator species compared to eggs of pest species even in the same habitat (Cottrell \& Yeargan, 1998). In contrast, some species of coccinellids feed on eggs of other coccinellids (Cottrell, 2005). However, in C. montrouzieri conspecific and interspecific egg predation is absent. Predation by adults of $C$. montrouzieri on all larval stages, prepupa, and pupa of $S$. epius may be due to the sluggish nature of S. epius larvae; and prepupa and newly formed pupa are more prone to attack as they clear prey debris present on their back during the formation of prepupa.

All in all our study provides an insight into the possible complex inter- and intraspecific predatory phenomena occurring in S. epius and C. montrouzieri in the field. In the presence of prey, the absence of cannibalism and IGP in these two 
species suggests that they can be employed together in biological control when a prey population is abundant. C. montrouzieri larvae may serve as an additive along with voracious $S$. epius larvae in the control of mealybugs. Both $S$. epius and $C$. montrouzieri can maintain a stable coexistence in abundant prey populations and at the time of prey scarcity and at patchy prey habitats they may possess asymmetric IGP. Thus, $C$. montrouzieri may dominate the guild and becomes a threat to larvae of S. epius under the situation of total absence of prey. This first information is helpful to use these two predator species in the biological control of mealybugs.

\section{References}

Agarwala, B.K. \& Yasuda, H. (2001) Overlapping oviposition and chemical defence of eggs in two co-occurring species of ladybird predators of aphids. Journal of Ethology 19, 47-53.

Baumgartner, J., Bieri, M. \& Delucchi, V. (1987) Growth and development of immature life stages of Propylea 14-punctata L. and Coccinella 7-punctata L. (Coleoptera: Coccinellidae) simulated by the metabolic pool model. Entomophaga 32, 415-423.

Bentley, W. (2002) Vine Mealybug, Planococcus ficus, Management for North and Central Coast Vineyards. ucce.ucdavis.edu/ files/fileibrary/2002/4381.pdf.

Browning, H.W. (1992) Overview of biological control of homopterous pests in the Caribbean. Florida Entomologists 75, 440-446.

Cardinale, B.J., Harvey, C.T., Gross, K. \& Ives, A.R. (2003) Biodiversity and biocontrol: emergent impacts of a multienemy assemblage on pest suppression and crop yield in an agroecosystem. Ecological Letters 6, 857-865.

Chacko, M.J., Krishnamoorthy Bhat, P., Anand Rao, L.V., Deepak Singh, M.B., Ramanarayan, E.P. \& Sreedharan, K. (1978) The use of the ladybird beetle, Cryptolaemus montrouzieri, for the control of coffee mealybugs. Journal of Coffee Research 8, 14-19.

Chang, G.C. (1996) Comparison of single versus multiple species of generalist predators for biological control. Environmental Entomology 25, 207-212.

Clausen, C.P. (1978) Introduced Parasites and Predators of Arthropod Pests and Weeds: A World Review. USDA-ARG, Agriculture Handbook No. 480, Washington, DC.

Cottrell, T.E. (2005) Predation and cannibalism of lady beetle eggs by adult lady beetles. Biological Control 34, 159-164.

Cottrell, T.E. \& Yeargan, K.V. (1998) Intraguild predation between an introduced lady beetle, Harmonia axyridis (Coleoptera: Coccinellidae), and a native lady beetle, Coleomegilla maculata (Coleoptera: Coccinellidae). Journal of Kansas Entomological Society 71, 159-163.

Denno, R.F. \& Finke, D.L. (2006) Multiple predator interactions and food-web connectance: implications for biological control. pp. 45-70 in Brodeur, J. \& Boivin, G. (Eds) Trophic and Guild Interactions in Biological Control. Netherlands, Springer.

Denoth, M., Frid, L. \& Myers, J.H. (2002) Multiple agents in biological control: improving the odds? Biological Control 24, 20-30.

Dethier, V.G. (1937) Cannibalism among lepidopterous larvae. Psyche 44, 110-115.

Dinesh, A.S. \& Venkatesha, M.G. (2011a) Prey consumption by mealybug predator, Spalgis epius on pink hibiscus mealybug (Maconellicoccus hirsutus). Phytoparasitica 39, 11-17.
Dinesh, A.S. \& Venkatesha, M.G. (2011b) Predation of the apefly, Spalgis epius (Lepidoptera: Lycaenidae) on citrus mealybug, Planococcus citri (Hemiptera: Pseudococcidae). Biocontrol Science and Technology 21, 523-533.

Dinesh, A.S. \& Venkatesha, M.G. (2012) Effect of temperature on the life history and demographic parameters of Spalgis epius (Westwood) (Lepidoptera: Lycaenidae), a candidate biological control agent of mealybugs (Hemiptera: Pseudococcidae). Biocontrol Science and Technology 22, 13511361.

Dinesh, A.S. \& Venkatesha, M.G. (2013a) Analysis of the territorial, courtship and coupling behavior of the hemipterophagous butterfly, Spalgis epius (Westwood) (Lepidoptera: Lycaenidae). Journal of Insect Behaviour 26, 149-164.

Dinesh, A.S. \& Venkatesha, M.G. (2013b) A quantified ethogram for oviposition behavior and oviposition preference in the hemipterophagous butterfly Spalgis epius (Westwood) (Lepidoptera: Lycaenidae). Journal of Ethology 31, 71-77.

Dinesh, A.S., Venkatesha, M.G. \& Ramakrishna, S. (2010) Development, life history characteristics and behaviour of mealybug predator, Spalgis epius (Westwood) (Lepidoptera: Lycaenidae) on Planococcus citri (Risso) (Homoptera: Pseudococcidae). Journal of Pest Science 83, 339-345.

Finke, D.L. \& Denno, R.F. (2003) Intra-guild predation relaxes natural enemy impacts on herbivore populations. Ecological Entomology 28, 67-73.

Franco, J.C., Gross, S., Carvalho, C.J., Blumberg, D. \& Mendel, Z. (2001) The citrus mealybug in citrus groves in Israel, Portugal and California: fruit injury and biological control as related to seasonal activity. Phytoparasitica 29, 86.

Gardiner, M.M. \& Landis, D.A. (2007) Impact of intraguild predation by adult Harmonia axyridis (Coleoptera: Coccinellidae) on Aphis glycines (Hemiptera: Aphididae) biological control in cage studies. Biological Control 40, 386-395.

Godfray, H.C.J. \& Pacala, S.W. (1992) Aggregation and the population dynamics of parasitoids and predators. American Naturalist 140, 30-40.

Grez, A.A., Viera, B. \& Soares, A.O. (2012) Biotic interactions between Eriopis connexa and Hippodamia variegata, a native and an exotic coccinellid species associated with alfalfa fields in Chile. Entomologia Experimentalis et Applicata 142, 36-44.

Heidari, M. \& Copland, M.J.W. (1992) Host finding by Cryptolaemus montrouzieri (Col., Coccinellidae) a predator of mealybugs (Hom., Pseudococcidae). Entomophaga 37, 621-625.

Hironori, Y. \& Katsuhiro, S. (1997) Cannibalism and interspecific predation in two predatory ladybirds in relation to prey abundance in the Weld. Entomophaga 42, 153-163.

Holt, R.D. \& Polis, G.A. (1997) A theoretical framework for intraguild predation. American Naturalist 149, 745-764.

Hoogendoorn, M. \& Heimpel, G.E. (2003) PCR-based gut content analysis of insect predators: use in field-caught predators. pp. 91-97 in Proceedings of the 1st International Symposium on Biological Control of Arthropods, Honolulu, Hawaii.

Joyce, A.L., Hoddle, M.S., Bellows, T.S. \& Gonzalez, D. (2001) Oviposition Behaviour of Coccidoxenoides peregrinus, a parasitoid of Planococcus ficus. Entomologia Experimentalis et applicata 98, 49-57.

Kim, C.W., Noh, Y.T. \& Kim, J.I. (1968) Study on the natural enemies proper in Korea attacking fall webworm, Hyphantria cunea Drury. Entomological Research Bulletin 4, 17-36.

Koch, R.L., Hutchison, W.D., Venette, R.C. \& Heimpel, G.E. (2003) Susceptibility of immature monarch butterfly, Danaus 
plexippus (Lepidoptera: Nymphalidae: Danainae), to predation by Harmonia axyridis (Coleoptera: Coccinellidae). Biological Control 28, 265-270.

Losey, J.E. \& Denno, R.F. (1999) Factors facilitating synergistic predation: the central role of synchrony. Ecological Application 9, 378-386.

Lucas, E., Coderre, D. \& Brodeur, J. (1998) Intraguild predation among aphid predators: characterization and influence of extraguild prey density. Ecology 79, 1084-1092.

Mani, M. (1995) Studies on the natural enemies of oriental mealybug, Planococcus lilacinus (CK1l.) (Homoptera: Pseudococcidae) in India. Journal of Entomological Research 19, 61-70.

Mani, M. \& Thontadarya, T.S. (1987) Development and feeding potential of coccinellid predator Cryptolaemus montrouzieri Mul. on the grape mealybug, Maconellicoccus hirsutus (Green). Journal of Biological Control 1, 19-22.

Mills, N. (2006) Interspecific competition among natural enemies and single versus multiple introductions in biological control. pp. 191-220 in Brodeur, J. \& Boivin, G. (Eds) Trophic and Guild Interactions in Biological Control. Netherlands, Springer.

Musser, F.R. \& Shelton, A.M. (2003) Factors affecting the temporal and within-plant distribution of coccinellids in corn and their impact on potential intra-guild predation. Environmental Entomology 32, 575-583.

$\mathrm{Ng}$, S.M. (1988) Observations on the foraging behavior of starved aphidophagous coccinellid larvae (Coleoptera: Coccinellidae) pp. 29-33 in Niemczyk, E. \& Dixon, A.F.G. (Eds) Ecology and effectiveness of Aphidophaga. SPB Academic, The Hague.

Omkar, XX., Gupta, A.K. \& Pervez, A. (2005) Attack, escape and predation rates of larvae of two aphidophagous ladybirds during conspecific and heterospecific interactions. Biocontrol Science and Technology 16, 295-305.

Perez-Jaggi, R. (1995) Yellow Variegation in Coleus blumei (Bentham) and Selected Life History Traits of Cryptolaemus montrouzieri Mulsant (Coleoptera: Coccinellidae). MS Thesis, Purdue University, West Lafayette, IN.

Polis, G.A. \& Holt, R. (1992) Intraguild predation: the dynamics of complex tropic interactions. Trends in Ecology and Evolutions 7, 151-154.

Polis, G.A., Myers, C.A. \& Holt, R.D. (1989) The ecology and evolution of intraguild predation: potential competitors that eat each other. Annual Review of Ecology and Systematics 20, 297-330.

Prasad, R.P. \& Snyder, W.E. (2004) Predator interference limits fly egg biological control by a guild of ground-active beetles. Biological Control 31, 428-437.

Rosenheim, J.A. (2005) Intraguild predation of Orius tristicolor by Geocoris spp. and the paradox of irruptive spider mite dynamics in California cotton. Biological Control 32, 172-179.

Schausberger, P. \& Walzer, A. (2001) Combined versus single species release of predaceous mites: predator-predator interactions and pest suppression. Biological Control 20, 269-278.
Schellhorn, N.A. \& Andow, D.A. (1999) Mortality of coccinellid (Coleoptera: Coleoptera) larvae and pupae when prey become scarce. Environmental Entomology 28, 1092-1100.

Serrano, M.S. \& Lapointe, S.L. (2002) Evaluation of host plants and a meridic diet for rearing Maconellicoccus hirsutus (Hemiptera: Pseudococcidae) and its parasitoid Anagyrus kamali (Hymenoptera: Encyrtidae). Florida Entomologists 85, 417-425.

Shu, C.R. \& Yu, C.Y. (1985) An investigation on the natural enemies of Hyphantria cunea. Natural Enemies Insects 7, 91-94.

Snyder, W.E. \& Ives, A.R. (2001) Generalist predators disrupt biological control by a specialist parasitoid. Ecology 82, 15711583.

Snyder, W.E., Ballard, S.N., Yang, S., Clevenger, G.M., Miller, T. D., Ahn, J.J., Hatten, T.D. \& Berryman, A.A. (2004) Complementary biocontrol of aphids by the ladybird beetle Harmonia axyridis and the parasitoid Aphelinus asychis on greenhouse roses. Biological Control 30, 229-235.

SPSS Inc. (2008) SPSS® for windows, Rel. 17.0.0. (Computer program) SPSS Inc. Chicago, Illinois.

Straub, C.S. \& Snyder, W.E. (2006) Species identity dominates the relationship between predator biodiversity and herbivore suppression. Ecology 87, 277-282.

Symondson, W.O.C., Sunderland, K.D. \& Greenstone, M.H. (2002) Can generalist predators be effective biocontrol agents? Annual Review of Entomology 47, 561-594.

Venkatesha, M.G. (2005) Why is homopterophagous butterfly, Spalgis epius (Westwood) (Lepidoptera: Lycaenidae) amyrmecophilous? Current Science 89, 245-246.

Venkatesha, M.G. \& Dinesh, A.S. (2011) Mass rearing of Spalgis epius (Lepidoptera: Lycaenidae), a potential predator of mealybugs (Hemiptera: Pseudococcidae). Biocontrol Science and Technology 39, 929-940.

Venkatesha, M.G. \& Shashikumar, L. (2006) Natural balance between insect pests and their enemies in Biodiversity Park of Bangalore University. pp. 333-339 in Ignacimuthu, S.J. \& Jayaraj, S. (Eds) Biodiversity and Insect Pest Management. New Delhi, Narosa Publishing House.

Venkatesha, M.G., Shashikumar, L. \& Gayathri Devi, S.S. (2004) Protective devices of the carnivorous butterfly, Spalgis epius (Westwood) (Lepidoptera: Lycaenidae). Current Science 87, 571-572.

Wagner, D.J. \& Wise, D.W. (1996) Cannibalism regulates densities of young wolf spiders: evidence from field and laboratory experiments. Ecology 77, 639-652.

Wilby, A. \& Thomas, M.B. (2002) Natural enemy diversity and pest control: patterns of pest emergence with agricultural intensification. Ecology Letters 5, 353-360.

Yasuda, H., Kikuchi, T. \& Kindlmann, P. (2001) Relationships between attack and escape rates, cannibalism and intraguild predation in larvae of two predatory ladybirds. Journal of Insect Behavior 14, 373-383.

Zar, J.H. (1984) Biostatistical Analysis. 2nd edn. Englewood Cliffs, NJ, Prentice Hall. 